\title{
Gastroprotective Effect of Azadirachta indica Leaves (Neem) Extract on Aspirin Induced Gastric Ulcer in Rats
}

\author{
Sultana Farzana ${ }^{1}$, Supti Prava Saha², Nashid Sultana ${ }^{3}$, Md. Ismail khan ${ }^{4}$
}

\begin{abstract}
Background: Gastric ulcer is one of the common diseases worldwide. Different parts of Azadirachta indica (Neem) tree has different uses in medicine for its beneficial properties and its leaves are also known to have anti ulcerant effect. Objective: This study was conducted to find out the protective role of Azadirachta indica (Neem) extract in the development of gastric ulcer. Materials and method: The study comprised of 30 Albino rats: Group-A, Group-B, Group-C, Group-D and Group-E having 6 rats in each group. The experiment was divided into 2 parts: Experiment-1 and Experiment-2. Experiment-1 comprised of Group-A and Group-B where Group-A served as control and was provided with normal saline $(2 \mathrm{ml} / \mathrm{kg}$ body $\mathrm{wt}$ ). In group- $B$ rats ulcer was produced by administration of aqueous suspension of Aspirin (200 mg/kg body wt). All the rats were sacrificed after 4 hours to confirm gastric ulcer by histopathology. In Experiment-2, rats of Group-C served as disease control group and provided with normal saline $(2 \mathrm{ml} / \mathrm{kg}$ body $\mathrm{wt})$. Group-D was provided with alcoholic extract of Azadirachtaindica leaves $(150 \mathrm{mg} / \mathrm{kg}$ body wt) and Group-E was provided with Ranitidine suspension $(20 \mathrm{mg} / \mathrm{kg})$. After 8 days of treatment, animals were fasted for 24 hours. Then aqueous suspension of Aspirin (200 mg/kg body wt) was administered and after 4 hours all rats were sacrificed. Gross and microscopic examinations were performed to evaluate the results. Results: Histologically Aspirin treated rats showed ulcerated mucosa. Pretreatment with Neem extract showed protection against Aspirin induced gastric mucosal damage which was statistically highly significant $(p<0.001)$. Conclusion: The study suggests that pretreatment with Azadirachta indica (Neem) leaves extract may be useful in prevention of Aspirin induced gastric ulcer.
\end{abstract}

Key words: Gastric ulcer; neem leaves.

Delta Med Col J. Jul 2019;7(2):61-65

\section{Introduction}

The incidence of peptic ulcer disease (PUD) has declined in the recent years although the economic burden, morbidity, and mortality due to the disease are huge. ${ }^{1}$ Peptic ulcer is a break in the gastric or duodenal mucosa that arises when the normal mucosal defensive factors are impaired or are overwhelmed by aggressive luminal factors such as acid and pepsin. There are three major causes of

1. Assistant Professor, Dept. of Pharmacology, Ibrahim Medical College, Dhaka, Bangladesh.

2. Lecturer, Dept. of Microbiology, Ibrahim Medical College, Dhaka, Bangladesh.

3. Associate Professor, Dept. of Pharmacology, Delta Medical College, Dhaka, Bangladesh

4. Vice Chancellor, Chittagong Medical University, Chattogram, Bangladesh.

Correspondence: Dr. Sultana Farzana. e-mail: sultanabd4349@gmail.com 
peptic ulcer disease: non-steroidal inflammatory drugs (NSAIDs), chronic Helicobacter pylori infection and an acid hyper secretory state such as Zollinger-Ellison syndrome. Over 99\% of peptic ulcers are caused by infection with $\mathrm{H}$. pylori or by uses of NSAIDs. ${ }^{2}$ Aspirin, which inhibits cyclooxygenase, is rapidly deacetylated to salicylate. Salicylate is toxic to cells and affects mucosal barrier function, reduces cytosolic adenosine triphosphate, stimulates sodium transport, and increases proton dissipation from surface epithelial cells. Cyclooxygenase inhibition makes the gastric mucosa more susceptible to injury, inhibits mucus and bicarbonate secretion, alters the physicochemical nature of mucus, stimulates fundic but not antral $[3 \mathrm{H}]$ thymidine incorporation, and reduces epithelial surface hydrophobicity. ${ }^{3}$ It decreases mucin, surface active phospholipids, bicarbonate secretion and mucosal proliferation and also produces damage by formation of free radicals. ${ }^{4}$ Several agents that enhance the healing of peptic ulcers may be divided into three categories: 1) Acid anti secretory agents a) H2 receptor blocker (ranitidine, famotidine, cimetidine) b) Anti muscarinic agent ( pirenzepine, telenzepine) c) Proton pump inhibitor (omeprazole, lansoprazole, pantoprazole), 2) Mucosal protective agents (sucralfate, carbenexolone, prostaglandin analogue), and 3) Agents that promote eradication of H. pylori. ${ }^{5}$ Neem or Azadirachta indica is native to tropical South East Asia. It is a tree which has been used for thousands of years in agricultural and medicine fields for its beneficial properties. Neem has been extensively used in Ayurvedic, unani and homeopathic medicine. ${ }^{6}$ Neem oil, bark and leaf extracts have been therapeutically used as folk medicine to control leprosy, intestinal helminthiasis, respiratory disorders, constipation, rheumatism, chronic syphilitic sores, skin diseases and malaria. ${ }^{7,8}$ Neem oil and leaf contain mainly glycerides and $2 \%$ bitter principles. Among them Nimbidin, Nimbin, Nimbinin and Nimbidol are important. Neem leaves contain some ascorbic acid and some amino acid also. ${ }^{9}$ The values of the leaves have been proven by their immune modulatory, anti-inflammatory, anti hyperglycemic, anti ulcer, anti malarial, anti fungal, anti bacterial, anti viral, antioxidant, anti mutagenic and anti carcinogenic property. ${ }^{10}$ Although to prevent gastric damage, many of the drugs are available like PPI, H2 blocker, sucralfate, they also have adverse effect and are also expensive. Newer drugs are continuously searched worldwide which have minimum adverse effect and maximum benefit. We therefore planned to evaluate gastro protective potential of neem leaves extract following consumption of Aspirin.

\section{Materials and method}

The study was conducted in the department of Pharmacology, Dhaka Medical College in collaboration with department of Pathology, Dhaka Medical College and Department of Chemistry of Dhaka University, Dhaka.

\section{Experimental animals}

The experiment was carried out on a total number of 30 healthy Albino rats. The rats were aged between 18-20 weeks of both sex and weighing between 150-175 gm. They were kept in medium sized metallic cages in animal house of the Pharmacology department at Dhaka Medical College, Dhaka. They were allowed to live at room temperature, fed on standard pellets of rat food and allowed to drink tap water.

\section{Preparation of plant extract}

The extract was prepared in the department of Chemistry of Dhaka University, Dhaka. The leaves were dried and crushed into coarse powder which was used for extraction with alcohol $(95 \%$ $\mathrm{v} / \mathrm{v})$ using soxhlet apparatus. The extract was evaporated under vacuum. The extractive $(\% \mathrm{w} / \mathrm{w})$ of the alcoholic dry extract was $4.25 \%$.

\section{Drugs and chemicals}

1) Aspirin was bought from local medicine shop, Dhaka, Bangladesh. 
2) Ranitidine was bought from local medicine shop, Dhaka and diluted with water to make suspension.

3) $0.9 \%$ sodium chloride (Normal saline) and distilled water were supplied by the department of Pharmacology of Dhaka Medical College, Dhaka, Bangladesh.

\section{Experimental design}

The experiment was divided into 2 parts: Experiment-1 and Experiment-2.

\section{Experiment-1}

It comprised of 12 rats which were divided into 2 groups each having 6 rats. Groups were labeled as Group-A and Group-B.

Group-A: This group served as control group and they were provided with normal saline $(2 \mathrm{ml} / \mathrm{kg})$ orally by gastric tube.

Group-B: This group was provided with aqueous suspension of Aspirin (200 mg/kg) orally by gastric tube.

After 4 hours all rats were sacrificed by an overdose of diethyl ether. Stomach was collected for gross and histopathological study. Experiment on this group was carried out to evaluate the effect of aqueous suspension of Aspirin in rats.

\section{Experiment-2}

It comprised of 18 rats. They were divided into 3 groups each containing 6 rats labeled as Group-C, Group-D and Group-E.

Group-C: This group served as disease control group and they were provided with normal saline ( $2 \mathrm{ml} / \mathrm{kg}$ ) orally by gastric tube for 8 days.

Group-D: They were provided with alcoholic extract of Azadirachta indica leaves $(150 \mathrm{mg} / \mathrm{kg}$ body wt) orally by gastric tube for 8 days.

Group-E: They were provided with Ranitidine suspension $(20 \mathrm{mg} / \mathrm{kg})$ orally by gastric tube for 8 days.
After 8 days of treatment, animals were fasted for 24 hours. Then aqueous suspension of Aspirin 200 $\mathrm{mg} / \mathrm{kg}$ was given. After 4 hours all rats were sacrificed and were prepared for dissection. Experiment in this group was carried out to evaluate the gastro-protective effect of alcoholic extract of Azadirachta indica leaves on Aspirin induced gastric ulcer in rats as compared to Ranitidine.

\section{Histological procedure}

Each stomach was cut opened along the greater curvatures and rinsed up with tap water. Lesions in the glandular part of the stomach were observed macroscopically. Thus the whole mucosa was examined with the help of dissecting microscope (x20) with the aid of square-grid eye piece $\left(1 \mathrm{~mm}^{2}\right)$. Detailed examination of mucosal surface and the measurement of small lesion length, breadth and area were done.

\section{Morphological parameter}

1) Number of lesion (mean $\pm \mathrm{SD}$ ) per rat in each group.

2) Individual lesion length and breadth in millimeter (mean $\pm \mathrm{SD}$ ) for each group.

3) Individual lesion area (length $x$ breadth) in square millimeter (mean $\pm \mathrm{SD}$ ) for each group.

4) Mean ulcer index (sum of lengths of all lesions in each stomach) in millimeter for each group.

\section{Ulcer index}

Ulcer index was counted from the glandular portion. Each lesion was measured along the greatest length and evaluated single according to their dimensions and severity. Ulcer index $=10 / X$; ( $\mathrm{X}=$ area of glandular portion of stomach / area of ulceration in $\mathrm{mm}^{2}$ scale). ${ }^{11}$

\section{Statistical analysis}

Data were expressed as Mean \pm standard deviation (SD). Student's t-test was then used to determine 
the level of significance. $\mathrm{p}<0.05, \mathrm{p}<0.01$ and $\mathrm{p}$ $<0.001$ were selected as level of significance.

\section{Results}

Table I shows the effect of aqueous suspension of Aspirin in rats. Group-A had no lesion in the stomach but in group-B there were ulcers of different dimensions. Thus aqueous suspension of Aspirin was shown to have strong ulcer producing effects in rats.

Table I: Effect of Aspirin on gastric mucosa

\begin{tabular}{lcc}
\hline Parameters & $\begin{array}{c}\text { Group-A(n=6) } \\
\text { Mean } \pm \text { SD }\end{array}$ & $\begin{array}{c}\text { Group-B(n=6) } \\
\text { Mean } \pm \text { SD }\end{array}$ \\
\hline Mean lesion length in $\mathrm{mm}$ & 0 & $6.52 \pm 3.80$ \\
Mean lesion breadth in $\mathrm{mm}$ & 0 & $1.63 \pm 1.35$ \\
Mean lesion area in $\mathrm{mm}^{2}$ & 0 & $13.58 \pm 15.91$ \\
Mean lesion index in $\mathrm{mm}^{2}$ & 0 & $31.50 \pm 9.61$ \\
\hline
\end{tabular}

Table II shows the comparative gastro-protective effects of Azadirachta indica and Ranitidine on rats.

Table II: Effects of alcoholic extract of Azadirachta indica and Ranitidine on gastric mucosa

\begin{tabular}{lccc}
\hline Parameters & $\begin{array}{c}\text { Group-C }(\mathbf{n}=\mathbf{6}) \\
\text { Mean } \pm \text { SD }\end{array}$ & $\begin{array}{c}\text { Group-D (n=6) } \\
\text { Mean } \pm \text { SD }\end{array}$ & $\begin{array}{c}\text { Group-E (n=6) } \\
\text { Mean } \pm \text { SD }\end{array}$ \\
\hline Mean lesion length in $\mathrm{mm}$ & $6.75 \pm 3.71$ & $3.48 \pm 2.25$ & $2.38 \pm 1.84$ \\
Mean lesion breadth in $\mathrm{mm}$ & $1.63 \pm 1.29$ & $0.77 \pm 0.48$ & $0.64 \pm 0.66$ \\
Mean lesion area in $\mathrm{mm}^{2}$ & $13.66 \pm 15.14$ & $1.30 \pm 3.55$ & $2.58 \pm 5.26$ \\
Mean lesion index in $\mathrm{mm}^{2}$ & $36.00 \pm 11.08$ & $14.51 \pm 2.47$ & $9.91 \pm 2.82$ \\
\hline
\end{tabular}

\section{Comparing Group-D with Group-C (Control)}

There was a significant reduction in ulcer length, ulcer breadth, ulcer area and ulcer index seen in group-D which was pre-treated with alcoholic extract of Azadirachta indica. Results were highly significant $(p<0.001)$. Thus alcoholic extract of Azadirachta indica showed to have a significant gastro-protective effect in rats.

\section{Comparing Group-D with Group-E}

Reduction of ulcer length, ulcer breadth, ulcer area and ulcer index was not significant between the groups $p>0.05$. Thus Azadirachta indica showed to have equal efficacy as Ranitidine in gastro-protection in experimental rats.

\section{Discussion}

The present study was carried out to evaluate the gastro-protective effect of Azadirachta indica leaves on experimentally induced gastric ulcer in rats. For this purpose effects of alcoholic extract of Azadirachta indica leaves were demonstrated in Aspirin induced gastric damage in rats. In addition histological studies of rat stomach following administration of alcoholic extract of Azadirachta indica leaves and Aspirin were also done. The leaves have been used to treat a number of gastrointestinal disorders. ${ }^{12}$ Although Azadirachta indica has not been well established in promoting protection toward gastric mucosa, many other properties such as antioxidant and anti-inflammatory activity can be applied in medical science.

In this study, aqueous suspension of Aspirin was used as an agent to induce stomach ulcer in rats. The dose and route of administration were selected to according to the study by Yinusa et. $\mathrm{al}^{12}$, and Aspirin $(200 \mathrm{mg} / \mathrm{kg})$ suspended in $1 \%$ sodium carboxyl methyl cellulose was given for production of experimental gastric ulcer.

There was remarkable and significant change in the mean value of ulcer number, ulcer length, breadth, ulcer area and ulcer index in rats treated with alcoholic extract of Azadirachta indica as compared with that of in rats produced with normal saline. This was consistent with other reported works in different countries. ${ }^{13-16}$ The experimental and histological findings provided support for the gastro-protective effect of alcoholic extract of Azadirachta indica leaves in Aspirin induced gastric damage in rats. Pre-treatment with Azadirachta indica leaves prevented histopathological changes such as congestion, hemorrhage, edema, inflammatory and dysplastic changes. So, the current study demonstrated that Azadirachta indica leaves have gastro-protective activity. 


\section{Conclusion}

The observation and result of this study provide a rationale for use of Azadirachta indica leaves in the development of new drug for treatment and prevention of peptic ulcer disease. This study establishes that Azadirachta indica (Neem) leaves extract has gastro-protective ability following consumption of Aspirin. On the basis of present study, it is suggested that further large scale experimental studies as well as clinical trials should be conducted to develop it as a useful antiulcer agent for human.

\section{References}

1. Yuan Y, Padol IT, Hunt RH. Peptic Ulcer Disease Today. Nat Clin Pract Gastroenterol Hepatol 2006;3:80-89.

2. Mcquaid KR. Alimentary Tract. In: Current Medical Diagnosis and Treatment. 46th ed. Philadelphia, New York: McGraw Hill; 2007. p. 548-663.

3. Kauffman G. Aspirin-Induced Gastric Mucosal Injury: Lessons Learned From Animal Models. Gastroenterology. 1989;96:606-14.

4. Scheiman JM. NSAIDs, Gastrointestinal Injury, and Cytoprotection. Gastroenterology Clinics of North America. 1996;25(2):279-98.

5. Valle JD. Peptic Ulcer Disease and Related Disorders. In: Harrison's Principles of Internal Medicine. 16th ed. Philadelphia, New York: McGraw Hill; 2005. p. 1746-62.

6. www.infinityfoundation.com [Internet]. Agrawal DP. Medicine Properties of Neem. 2005 [cited 2015 Jul 9]. Available from: http://www. infinityfoundation.com/.

7. Conrick J. Neem - The Ultimate Herb Literature from
Pure Gar Neem: A Tree for Solving Global Problems. National Academy Press. 2005.

8. Biswas K, Chattopadhyay I, Banergee RK, Bandyopadhyay U. Biological Activities and Medicinal Properties of Neem (Azadirachta indica). Current Sci. 2002;82:1336-45.

9. Ghani A. Bheshaja Biggan [in Bangla]. 1st ed. Bangla Academy: Dhaka; 1995. p. 60-62.

10. Subapriya R, Nagini S. Medicinal Properties of Neem Leaves: A Review. Curr Med Chem Anticancer Agents. 2005;5(2): 149-56.

11. Ganguly AK,Bhatnagar OP. Effects of Bilateral Adrenalectomy on the Production of Resistant Ulcer in the Stomach of Albino Rats. Can J Physiol Pharmacol 1973;51:748-50.

12. Raji Y, Ogunwande IA, Osadebe CA, John G. Effect of Azadirachta indica Extract on Gastric Ulceration and Secretion in Rats. J Ethnopharmacol. 2004;90:167-70.

13. Garg GP, Nigam SK, Ogle CW. Antiulcer Effects of the Leaves of the Neem Tree. Planta Med. 1993;59(3):215-17.

14. Bhajoni PS, Meshram GG, Lahkar M. Evaluation of the Antiulcer Activity of the Leaves of Azadirachta indica: An Experimental Study. Integr Med Int. 2016;3:10-16.

15. Chattopadhyay I, Nandi B, Chatterjee R, Biswas K, Bandyopadhyay U, Banerjee RK. Mechanism of Antiulcer Effect of Neem (Azadirachta indica) Leaf Extract: Effect on $\mathrm{H}+-\mathrm{K}+$ ATPase, Oxidative Damage and Apoptosis. Inflammo Pharmacology. 2004;12(2):153-76.

16. Mohapatra BB, Das MC, Dinda SC, Nagoji KEV. Antiulcer Activity of Aqueous and Ethanolic Leaf Extract of Neem (Azadirachta indica) in Albino Rats. Journal of Pharmacy Research. 2012;5(3):1571. 